\title{
Imaginarios contrapuestos: El desierto de Atacama percibido desde la región y mirado desde la nación ${ }^{1}$
}

\section{Contrasting Imaginaries: The Atacama Desert Perceived from the Region and Observed from the Nation}

\author{
José Antonio González Pizarro \\ Universidad Católica del Norte. Antofagasta. Chile
}

\section{RESUMEN}

Basándose en las categorías de Cornelius Castoriadis, el autor examina los imaginarios sociales sobre el desierto de Atacama desde el siglo XVI hasta el Xx. Pone de relieve cómo se fueron construyendo en la historia los distintos imaginarios para situarse en la contraposición entre el establecido en la nación chilena - centrado en los elementos de adversidad, esterilidad y lo inhóspito, todo lo cual proyectó una negatividad textualy el construido en la región, repleto de variados simbolismos en torno al desafío, la ocupación y la potencialidad de la naturaleza, que afianzó la empatía de la literatura nortina con la épica humana del asentamiento en el desierto.

Palabras clave: Chile, Desierto, Imaginarios sociales, Literatura nortina.

\section{SUMMARY}

The author draws on Cornelius Castoriadis' categories to examine the social imaginaries on the Atacama Desert from the $16^{\text {th }}$ to the $20^{\text {th }}$ centuries. He emphasizes the manner in which different imaginaries came to be constructed historically over time to the point of bringing about a contrast between the imaginary of the country - centered on adversity, sterility and desolation, thereby projecting a textual negativity about Atacama- and that of the region, full of varying symbolisms signifying challenge, occupation and the potentiality of nature. The latter imaginary strengthened the empathy of the northern literature toward the human epic of peopling the desert.

Key words: Chile, Desert, Social Imaginaries, Northern literature.

\footnotetext{
${ }^{1}$ El trabajo forma parte del proyecto Fondecyt 1051093 y de la Iniciativa Científica
} Núcleo Milenio "Ciencia Regional y Políticas Públicas", de la Universidad Católica del Norte. 
INTRODUCCIÓN SOBRE EL PAISAJE Y EL SUJETO. ALGUNAS DISQUISICIONES

Una aproximación al tema en lo inmediato exige plantearnos dos preguntas medulares: ¿Qué es lo existente en el desierto? De nuestra respuesta dependerá lo que encontremos en el páramo. Pero, también dependerá de privilegiar algunos de nuestros sentidos para conocer. En esta perspectiva, lo que se hace patente, lo que se halla en la superficie, apunta a delatar lo inmediato a nuestra mirada, que caracteriza la aproximación tanto del transeúnte como del forastero al territorio. O bien, nos detendremos a averiguar la causalidad del poblamiento, a buscar lo oculto en el yermo. Ambas posibilidades abren otro camino sobre el asunto. ¿Cuál es el criterio de verdad que deberemos aplicar al paisaje que nos ocupa? Aquel que nos dirige hacia la constatación de que lo real es lo existente. Por lo tanto, sería la adecuación entre nuestra mente y el objeto, la adecuación de lo observado con lo sabido sobre aquellos terrenos áridos, lo que daría la veracidad. En tal planteamiento, las condiciones del clima sobre el espacio fundamentarían la conceptualización del desierto. O podríamos tender hacia lo que se oculta a la mirada fugaz sobre el espacio. En tal orientación deberíamos preguntarnos sobre el desvelamiento de las entrañas del páramo, con lo cual asignaríamos otra arista a lo constitutivo del desierto en la actual segunda región: la valorización de los recursos mineros y su importancia económica gravitando en lo regional.

La siguiente pregunta fundamental es ¿Quién mira y quién posee la visión? Mira el que atraviesa el desierto sin ánimo de permanecer: el forastero, el turista, el viajero. Los que asignan importancia a la soledad y a la aridez. La inmensidad del espacio no los interpela en la dimensión cósmica ni menos en la eventualidad de la historia en aquellas latitudes. La visión se reserva al pionero, al "empampado", a toda la tipología humana relacionada con la minería del lugar (desde el "baqueano", "cateador" hasta los "barreteros" y "carrilanos") pero, también, al que ha domeñado la adversidad, el que se ha asentado en el desierto y ha transformado partes de lo inhóspito en lugares de vida, campamentos y ciudades. La visión encierra no sólo lo cognitivo esencial que fundamenta la permanencia (los recursos mineros), sino también la vinculación de su existencia al devenir de lo construido, hasta incluso llegar a fundirse con el paisaje. El paisaje moldea su carácter y lo transforma en un ser seco, hosco, franco, esforzado. Logra articular una fisonomía humana tan potente como el hombre del sur, anotará el escritor Manuel Rojas (1961: 821):

El verdadero nortino es seco, se da y da menos largona; es más exigente en todo, más callado; hasta se puede decir que es más trabajador. La pampa lo hace así, el sol, la soledad. 
La relación entre paisaje y sujeto es de un dinamismo dialéctico. Parte de la fortuna de la permanencia humana depende de las leyes que regulan el comercio de las riquezas del páramo, los repetidos ciclos de bonanza y depresión de la minería regional. El infortunio representa para el nortino la pérdida del horizonte de su habitar en el yermo: el desenganche de la oficina o del campamento minero, la cesantía, la "repatriación" a su lugar natal. El éxito se traduce en la reafirmación emocional de pertenecer a la pampa salitrera y no al mero desierto y ello simboliza la trascendencia de un modo de ver, sentir y vivir en el despoblado culturizado.

No obstante, esta relación activa entre paisaje y sujeto se deforma o altera cuando el ánimo del sujeto es su transitoriedad, lo efímero de la mirada de paso. No hay una conexión hacia un compromiso sentimental con el territorio; al contrario, lo observado le permite constatar el horror de la inmensidad de tierras secas y planas, y reafirmarse en su cuestionamiento a la viabilidad de su poblamiento.

LOS IMAGINARIOS CONTRAPUESTOS SOBRE EL DESIERTO DE ATACAMA

Queremos poner de relieve la dicotomía que se presenta en los imaginarios respecto del desierto de Atacama, en relación con lo antitético de lo regional/nacional, la incidencia de la mirada/visión y naturalmente a la vivencia del viajero/habitante. Acercarse a la noción del imaginario social nos facilitará la reunión de un sinnúmero de imágenes, percepciones, representaciones sociales, todas ellas producto de una época que, han incidido en la construcción de lo que es y significa el desierto de Atacama.

Nos apoyaremos en la definición, ya clásica, de Cornelius Castoriadis (1983-1989) para quien la sociedad misma constituye una "institución" donde lo simbólico atraviesa toda la acción humana. Todo lo inherente a la sociedad supera lo estrictamente individual o psíquico, y por consiguiente es un conjunto de significaciones imaginarias sociales construido a lo largo de la historia. Para él, la "historia es imposible e inconcebible fuera de la imaginación productiva o creadora, de lo que hemos llamado lo imaginario radical, tal como se manifiesta a la vez e indisolublemente en el hacer histórico, y en la constitución, antes de toda racionalidad explícita, de un universo de significaciones"(Castoriadis 1983: 253).

$\mathrm{Y}$ esto nos conduce a que toda representación encierra en cierta forma la imaginación radical. La sucesión continua de representaciones y de modo conectivo de los imaginarios sociales respectivos nos remite a que cada época histórica plantea a través de sus instituciones, sean éstas plurales, variadas e incluso dispares y antitéticas, sus propias significaciones que afectan a todo 
el entorno humano y a las propias generaciones. Otorgan valores a las realizaciones socio-culturales, pero también a las cosas que constituyen la alteridad del hombre en todos los ámbitos, lo natural y lo social. Este imaginario es una creación incesante e indeterminada en lo social-histórico y en lo psíquico. La propia "realidad" sería un producto de este imaginario y también la "racionalidad"

No existe en consecuencia una construcción de un imaginario social externo a la sociedad, donde las ideas o los referentes constituyan modelos a seguir. Es todo lo contrario: nada surge de la nada. Todo se hace, reconstruye, modifica, en la historia y con los hombres que conforman la sociedad. Estos pueden señalar ciertos hitos o referencias sincrónicas a lo largo de su vida, instituyendo el "tiempo identitario", que permite la parcelación o la congruencia de lo transcurrido. Dicho enfoque lo podemos adaptar a un antes y un después del ciclo salitrero en la región de Antofagasta. A su vez, el "tiempo imaginario", el de la significación, indeterminado y recurrente, encierra las causas y consecuencias no intencionales de lo deliberado-racional en la actuación humana. Y esto constituye en el desierto de Atacama la tensión significante de habitar lo inhóspito.

Este esquema se despliega en el espacio que centra nuestra atención en una serie de factores que concentran juicios procedentes de la ciencia, lo empírico, lo establecido en los textos, y a la vez impresiones, vivencias, apuestas, riesgos que traducen voluntades, emociones, suerte, exploraciones sin fin. Detrás de este conjunto de elementos, tanto irracionales, como lógicos, se esconden grupos, segmentos de personas que se han articulado con distintos imaginarios sociales respecto al desierto de Atacama. Estos han recogido, proyectado, refundido, recreado, los imaginarios sociales de sus generaciones, pero también han respondido desde sus propios paisajes, realidades económicas, apreciaciones ideológicas y constructos científicos.

La construcción del imaginario social nacional es un "magma de significaciones", como diría Castoriadis, cuyas razones provienen o se asientan en la reproducción social de los textos canonizados — desde y para la educación pública- que uniformizan las imágenes transmitidas en los libros de geografía e historia, deteniéndose en la constatación empírica clima/paisaje desconectado de las formas productivas operadas en el desierto. Se apoya en la transmisión de lo cognitivo, en la secuencia lógica de la inferencia de los elementos climáticos que dan significado al paisaje nortino. El rigor conceptual de lo que es el desierto arroja la imagen definida de lo anecúmene, lo inhóspito. Y secuencialmente, la iconografía, las láminas, quedan subordinadas a tal noción.

La construcción del imaginario social regional ha constituido una lucha tenaz entre lo asumido descriptivamente a partir de la ciencia, lo razonado, 
en definitiva, lo positivo; y lo aprehendido emotivamente, a partir de la vivencia, lo sentido-experimentado, en fin, lo fenomenológico. Este esquema apunta a situarnos en las antípodas de ambos imaginarios. Es un alineamiento que deliberadamente tiende a encerrar ideas-fuerzas sin pretender reconstruir marcos teóricos, pues los imaginarios sociales no constituyen teorías. Ahí está lo indeterminado de sus significantes.

Desde la región, el hombre se involucra con el paisaje. Hay una cercanía íntima. Se está en el desierto. Hay interpelación y reto geográfico al poblador. Existe la lucha entre permanecer y abandonar, entre formar $l u$ gares en el sentido heideggeriano o dejarse vencer por el espacio. Ser vencido por el paisaje es reafirmar el desierto: la huida del hombre, desertus.

La potente relación la recogió el escritor taltalino Mario Bahamonde (1951: 8), en uno de los cuentos más memorables de la literatura nortina,"Toda la pampa es un solo camino":

Caminar, caminar, caminar.... Los pasos......

De repente un sobresalto le apretó el corazón. ¿Estaría Perdido? ¿Se llegaría a alguna parte por esa dirección?

Solía ocurrir que la pampa fuera una mortaja de distancias. Pero no: el verdadero pampino es hermano de esta tierra y sabe entenderla. Sin embargo, se aferró a la botella como a una salvación.

Caminar desde la pampa de Iquique hasta el cantón de Antofagasta no es como andar jugando por las calicheras.

¡Al menos si no le dolieran tanto los ojos!

En esta construcción de la historia en el espacio del páramo, el hombre acude a toda su integridad; se apela a lo emotivo y también a lo racional. Todo ello articula un imaginario social regional.

A la inversa, la formación del imaginario social nacional concerniente al desierto queda constreñida a lo racional, a lo lógico. Hay separación entre sujeto y objeto. Es mirar e "imaginarse" colectivamente un espacio donde no habito, no estoy, no soy de él².

2 Fue el impacto de la imagen del desierto que tuvieron los viajeros y soldados procedentes de los valles centrales de Chile. Dos volúmenes del periodo de la guerra del Pacífico reflejaron el choque. Uno de ellos, Arturo Benavides (1971), no pudo disociar la aridez de los cerros de la costa con la escasa edificación que ostentaba Antofagasta, sintiendo angustia ante tal espectáculo. Igual impresión pudo consignar Eulogio Allendes (1880), al indicar que en la travesía de la pampa se deja sentir la ausencia de un árbol, un peñasco que pueda brindar sombra al transeúnte. Manuel Vicuña Urrutia (1995: 77), analizando algunos trozos de diarios de campañas y memorias científicas, acota: "Ni siquiera logro imaginarme el grado de eficacia con que el desierto de Atacama fue incorporado al universo mental de los chilenos. Sí sé que al menos hacia el año 1879, todavía el despoblado representaba en muchas oportunidades algo inimaginable para aquellos 


\section{El Despliegue De los imaginarios EN EL TIEMPO}

La complejidad del reto significó el desencuentro de la nación ante el significado del desierto de Atacama.

El "tiempo de la identidad" no sólo se acomoda a la inflexión de la industria salitrera en el desierto, sino al sentido de pertenencia de una forma de ver el desierto. Es decir, apunta a la cualidad perceptiva, a la génesis ontológica de los que ven desde la constatación del páramo, del no-verde, de la ausencia del campo y del bosque.

El sentido de pertenencia que va a constituir una referencia obligada a lo tempo-identitario comienza con la noción de nortinidad que la literatura se encargó de edificar ${ }^{3}$. El concepto recogió la adscripción al terruño del desierto donde se desplegó "otra" forma de vivir. Bajo la nortinidad pudieron acomodarse variadas percepciones, todas válidas, desde la articulación de la cultura en los poblados precordilleranos, principalmente los atacameños que bajaron hasta la depresión intermedia y dejaron sus senderos en el tránsito de la costa al interior, hasta las forjadas por los escritores que residieron o vivieron el páramo desde fines del siglo XIX.

Si la nortinidad tuvo fecha en el tiempo identitario - 1842- otra noción vino a sumarse para diferenciar aun más el acento: lo salitrero. Expresión textual que arrancó regionalmente de los cinco cantos de Las pampas

que no lo conocían”. En contraste con las imágenes de estos chilenos, oriundos del paisaje verde, se ha hecho notar, para el presente, cómo una parcela del yermo — San Pedro de Atacama - constituye también una visión de "espejo trizado" respecto de lo que es realmente aquella localidad colonial con lo que se espera encontrar, principalmente para los turistas norteamericanos y centroeuropeos, para los "que esta región y su inmenso desierto son uno de los últimos lugares lleno de magnetismo, exotismo y con un indudable aire de salvajismo indígena: Atacama es aventura y una ruptura con la 'cotidianidad' occidental [...] estos turistas son los más negativos, ante todo porque reclaman un exotismo puro que ni ha existido, ni que de hecho puede darse en una vida atacameña ajustada a una realidad vital suscrita a un desierto" (Anta Félez 1998:19-20).

${ }^{3}$ La importancia de José Joaquín Vallejo es notable en tal sentido. Para Sabella (1969: 15-16): "Hasta el 1 de febrero de 1842 el paisaje de Chile era único. Era el que elogiaba, en sus 'Cartas' a Carlos V, el Conquistador Pedro de Valdivia, exaltándolo por fértil y apacible. Pero, el 1. de febrero de 1842, en 'El Mercurio' de Valparaíso, José Joaquín Vallejo, nuestro avisor Jotabeche, describía a Copiapó. Amanecía la Literatura del Norte Chileno. Los fulgores del sur se opacaron, porque un paisaje seco, trágico y tremendo enseñaba su cara de piedras seculares... Por primera vez, llovía arena dentro de los libros chilenos, resonaba un adjetivo feroz ('riscos áridos'), se aludía a llanuras y a miserias de vegetación, el calor y la sed adquirían categoría de personajes, se deploraba la ausencia de galas naturales y el color negro se enfrentaba con el verde nacional, casi tres veces centenario". 
salitreras que Clodomiro Castro dio a conocer en 1896, y alcanzó su mayor difusión con Víctor Domingo Silva en $1905^{4}$. A este conjunto de locuciones se añadió otra, la de norte grande, cuya fecha fundacional es 1944 con la novela de Andrés Sabella, Norte Grande; lo que significó aunar la trilogía del obrero pampino, la industria calichera y el paisaje del desierto/pampa. Más tarde, se agregaría la dimensión mágica del desierto en la obra de Hernán Rivera Letelier, en la década de 1990. Todas estas escrituras han sido asumidas, internalizadas, recreadas colectivamente en las comunidades nortinas.

Este "tiempo de identidad" observado desde la nación es inexistente en lo ontológico. Sólo repara en los condicionantes económicos que ofrece el páramo y aun así, descontextualizado de la épica de la humanización del desierto. Hay cifras, volúmenes de exportaciones: no hay pálpito vital en su cronología.

Más elaboración encontramos en la dimensión del "tiempo de lo imaginario" en lo que atañe a la imaginación social nacional. Sin duda, en tal construcción encontramos una acumulación de impresiones de antigua data que hipotecan en gran medida otras posibilidades de "entender" el desierto. El "comprender" el desierto es una categoría, a nuestro entender, más propia de ser manejada por la comunidad regional, dado que involucra formas de aproximación al espacio desde varios niveles, desde lo cognitivo hasta lo emotivo. Ambos tiempos, el identitario como el imaginario, se relacionan fuertemente, notándose que el segundo no podría manifestarse sin la presencia del identitario. Como asevera Castoriadis (1989: 79):

Lo que ocurre no es mero acontecimiento repetido, sino manifestación esencial del orden del mundo, tal como es instituido por la sociedad en cuestión, ya sean en relación con el trabajo, los ritos, las fiestas o la política. Este es el caso en lo concerniente a los momentos cardinales del ciclo diario (amanecer, crespúsculo, mediodía, media noche) a las estaciones y a menudo a los años.

\footnotetext{
${ }^{4}$ Fue Sabella $(1948,1960)$ quien descubrió el opúsculo de Clodomiro Castro, Las pampas salitreras, editado en 1896 en Iquique. Acuñó la diferenciación entre "literatura del desierto" y "literatura del salitre". Para Sabella, el aporte de Víctor Domingo Silva fue decisivo al dar a conocer "la primera descripción artística de la pampa salitrera, minuciosa y apasionada”, por medio de sus cuentos La pampa trágica de 1921 (Silva 1938). Un crítico de una revista de la capital, Alfredo Peña (1952: 572-574), hacía notar que era necesario reactualizar La pampa trágica, tanto "como afirmación veraz que el libro contiene una concepción experiencial de la región nortina", como porque en ella "se encuentra el trozo palpitante del desierto, el afán de dar a conocer la vida difícil del norte de aquella época, a esos tipos que tienen su temple en el trabajo que embrutece y que les hace despreciar con arrogancia la vida".
} 
De esta manera, podemos distinguir tiempos identitarios que encuadran el surgimiento de los tiempos imaginarios. En ellos hay pluralidad de significaciones y apelaciones a las razones de éstas que, a veces, se explicitan o bien quedan latentes. Toda esta pluralidad, como hemos señalado, fundamenta un ahondamiento o un cuestionamiento de ciertas imágenes. Las que apuntan a "entender" el espacio quedan sujetas a la superficialidad de lo descriptivo; las que tratan de "comprender" encierran la asociación primordial del paisaje y el hombre. El paisaje despojado de la presencia del hombre es clave para el acercamiento del procedimiento de la construcción de la representación del desierto. Estos momentos históricos van a ser expuestos a continuación.

\section{EL IMAGINARIO DESIERTO LEGADO POR LOS CRONISTAS HISPANOS}

El tópico del "gran despoblado" fue la sintética imagen que legaron las plumas de las huestes españolas. El trazo de Pedro Mariño de Lobera, en su Crónica del Reino de Chile es el más representativo de todas las alusiones al espacio de entre sus compañeros de armas. Señala Mariño de Lobera (1969: 249-250):

Largo despoblado cuya travesía de ciento y veinte leguas donde pasaron trabajos excesivos por ser mui estéril y sin género de hierba, ni agua, ni otro pasto para los caballos [...] son tan ásperos y fríos los vientos de los más lugares deste despoblado, que acontece arrimarse al caminante a una peña y quedarse helado $\mathrm{y}$ yerto en pie por muchos años, que parece estar vivo [...] pocas aguas que fuera de lluvia hay en estos desiertos son tan inútiles, o están en jagüeyes a doce o trece leguas, o en algunos pocos manantiales donde corren clarísimas acequias de agua que convidan tanto con su transparencia, que se abalanzan a ella los que llegan sedientos, conociendo por experiencia cuánta verdad será que el deleite tiene la apariencia amena, dejando al gusto amargo más que acíbar. Ni es menos inútil el agua de un hermoso río deste despoblado, que siendo tan grata al aspecto como la pasada, apenas se ha tomado en la mano, cuando está vuelta en sal cuajada, de la cual sólo son sus riberas sin otra cosa.

La imagen es ajustada a la realidad física. Hay un cuidado de significar la extremada adversidad del clima. Muerte y engaño van de la mano de la inutilidad de cualquier esperanza. La desolación se transmite en términos contradictorios: la severidad del calor que imposibilita la existencia de hierba y agua se acomoda con el rigor del frío que asola al desierto. La oscilación térmica inhibe al hombre. Es el "despoblado infernal", que aludió Gonzalo Fernández de Oviedo en su Historia General de las Indias.

En uno de los márgenes del desierto, Gerónimo de Bibar (o Jerónimo de Vivar), otro español de la alborada conquistadora, anotará en su Cróni- 
ca y relación copiosa y verdadera de los reinos de Chile, la otra imagen del despoblado, abriendo una diversa realidad, al describir no sólo la habitabilidad en el valle de Atacama sino sus recursos naturales:

Hay en este valle de Atacama infinita plata y cobre y mucho estaño y plomo y gran cantidad de sal transparente. Sácase de barro de la tierra, en una manera de mina de metal, y cuando es caliente el sol, a la diez del día, descárgase la humedad que ha recibido de la noche pasada, y hace grande estruendo dentro en la mina con el calor del sol. Hay mucho alabastro [...] De la otra sal que se cría para bastimento común, hay en gran cantidad de salitrales y azufre.

Y un elemento importante que provoca la ruptura de la imagen consabida: se puede habitar el desierto.

Esta gente sirvió al inca, es gente dispuesta y bien vestidos, como los del Perú. Las mujeres son de buen parecer [...] Tienen sus adoratorios y ceremonias como los del Perú. Acostumbran y usan poner nombre a los niños que nacen [...] las armas que acostumbran son flechas y hondas. Es lengua por sí (Bibar 1966, II: 14).

Importa resaltar de esta imagen recóndita hasta bien entrado el siglo XX (la crónica se descubrió y editó en la década de 1960) la disonancia de lo aseverado por Aristóteles respecto a los condicionantes climáticos y el tipo de ser humano. Lo descrito por Bibar refiere no a un salvaje de los subtrópicos, por el contrario a hombres y mujeres con vida racional registrada en sus costumbres, lengua y organización socio-política. Esto último es relevante, no sólo por la fecha de su acotación — pleno siglo XVI- sino por el abordaje de la población en el desierto.

Las anotaciones de los viajeros del siglo XVIII no lograron alterar el núcleo de las impresiones heredadas. Así lo encontramos en Frézier ${ }^{5}$ y los Heuland (1800). Estos últimos en pos de un catastro mineralógico no pudieron alterar en nada lo ya sabido sobre el yermo. Algo vago quedó en sus registros sobre una eventual "utilidad" del desierto. Lo mismo pasa con el informe de Rafael Andreu y Guerrero (González Pizarro 1992, III: 299326) desde Paposo, hacia fines del siglo XviII. Estas imágenes del desierto impregnadas de adjetivos variados que cuestionan la buscada relación —no dan cuenta de los pozos de agua- van a proyectarse en el tiempo con fuerza, constituyendo el muro mental para el paso del hombre por el señalado espacio hasta comienzos del siglo XIX.

5 Amadeo Frézier (1902: 141-142) describió la aldea de Cobija y a sus habitantes - los indios changos - sobreviviendo en la costa del desierto mediante los pescados que intercambiaban con los indios atacameños por maíz y papa, reparando que "no hai en la aldea más que un hilito de agua un poco salado i en árboles solamente se ven cuatro palmeras i las higueras que pueden servir de seña para fondear [...] Este puerto es el que está más cerca de Lipes i de Potosí i, no obstante, está a más de cien leguas en país desierto". 
El DESIERTO EN EL DESPERTAR DEL SIGLO XIX. LA PLURALIDAD DE LOS IMAGINARIOS

Fue en el siglo XIX donde encontramos la convergencia/divergencia de los imaginarios. La difusión del imaginario social nacional como antípoda a la constitución del imaginario social regional. No sólo se enfatizan las impresiones de contraste de la eventualidad demográfica y la adversidad del espacio, sino la argumentación de criterios antilógicos, como son el científico/simbólico o la justipreciación de lo que constituye el desierto para el sureño, citadino, burgués ante el nortino, aventurero minero, esforzado pionero. Cada imaginario nacional esgrime una aproximación que es antitética en todo; reconocer la afirmación de uno es relegar las motivaciones del otro. Una arista para apreciar este conflicto perceptual estriba en lo realizado en el ensimismamiento necesario de los pioneros del desierto para acometer seguidamente la alteridad, en la perspectiva orteguiana. Reflexionar sobre el desierto fue acopiar lo indicado por detallados informes, $y$, a continuación, vislumbrarlo como espacio cuyo valor está en el riesgo de intervenir en procura de riquezas; o bien, la meditación va de la mano de la intuición, la "tinca" de perseguir la veta codiciada, escapando a la cadena de infortunios para construir una vida nueva, otra libertad, otra esperanza. El desierto se constituye en tierra promisoria, de utopía.

EL IMAGINARIO SOCIAL NACIONAL. LA NEGATIVIDAD TEXTUAL Y LA PERCEPCIÓN DE LO INHÓSPITO

El imaginario social nacional fue alimentado desde dos niveles. Por un lado, desde el paisaje en que se está situado y lo que significa y, por otro, desde la retroalimentación de la significación intuitiva.

Ha sido lugar común establecer el binario Vida/Muerte, Orden/Caos que refleja las tensiones de toda cultura. En este ámbito de cosas es posible consignar la dicotomía de paisajes. Frente al desierto se erige en el territorio nacional el campo que engloba tipos humanos contrapuestos al minero, como son el inquilino, el campesino y el hacendado. El campo, como el bosque, también lleva en sí la construcción de un imaginario fuertemente significativo. Es la vida en sí misma que concentra las energías de agua, madera, combustible, que hacen viable la habitabilidad de un lugar ${ }^{6}$.

\footnotetext{
${ }^{6}$ Una investigación en Francia y el País Vasco español (Dávila et.al 2004) ha arrojado distintos imaginarios sociales respecto del bosque, distinguiendo los que se encuentran dentro/fuera del sector forestal, que posibilitan "hacer ver" de una manera determinada al bosque: el "mítico" (el deseado: lo natural, silvestre, virgen), el "material" (donde
} 
Durante el siglo XIX las referencias tópicas al desierto provinieron de personajes situados en el centro del país. El propio ambiente influyó en su ánimo al describir otras entidades físicas. Los frisos sobre el desierto de Atacama que se difundieron en Chile desde mediados del siglo XIX fueron hechos por un conjunto de científicos notables en sus respectivas disciplinas que bosquejaron sus textos como informes oficiales. Aquellas impresiones no pudieron escapar a los cánones de la ciencia decimonónica (Saldivia 2003).

El relato primigenio correspondió a Rodolfo A. Philippi que, al igual que los hermanos Heuland, atravesó el desierto siguiendo el "Camino del Inca", desde Copiapó hasta San Pedro de Atacama. Philippi (1860: 105-107), en su Viaje al Desierto de Atacama hecho de orden del Gobierno de Chile en el verano 1853-1854, consignó:

La narración de mi viage ha puesto de manifiesto, que el Despoblado carece de todo recurso para hacerlo habitable y para permitir que sea una vía de comunicación y de comercio. Algunos hechos sin embargo parecen estar en contradicción con este aserto... De este hecho (la búsqueda de pozos en la expedición de Pedro de Valdivia) se puede deducir con toda certidumbre que las aguas en aquel tiempo eran tan escasas como lo son hoy en día, y de esta circunstancia pende la escasez, del pasto, del combustible, etc., en una palabra, la falta de agua crea un desierto y no una comarca fértil. ¿Pero tal vez la industria humana, ayudada de los progresos inmensos que las ciencias naturales han hecho en los últimos años podrá cambiar en algo la triste condición del desierto? ¿Se pueden utilizar las aguadas para formar alrededor de ellas chacras, alfalfales, pequeños pueblos? ¿Los pozos artesianos quizás darán un medio de regar y de establecer siembras y prados? He visto que muchas personas esperaban un gran éxito de los pozos artesianos. Desgraciadamente no hay ninguna esperanza de poder obtener estos pozos en el desierto. Ahora, no hay ningún pasto que el hombre cultiva para los animales, ninguna hortaliza que crezca en tal temperamento, y por eso creo, que no se puede sacar provecho de ellas. Me parece inútil demostrar que es sumamente difícil, para no decir imposible, construir ferrocarriles o telégrafos eléctricos por el Desierto.

Dejaba abierta la posibilidad de rectificar su última aseveración si se descubriesen "metales preciosos".

La atención hacia lo físico, lo superficial de lo observado, fue corroborada por el geógrafo Amado Pissis, quien, en su Informe sobre el desierto de Atacama, su jeología i sus productos minerales evacuado al gobierno chileno en 1877 , precisaba:

el bosque es objeto de algún tipo de gestión: el bosque urbanizado, para protegerlo, o ofertar servicios), el bosque "trabajado" (el destinado a la producción maderera, donde las percepciones van a contrapelo con el "mítico", mirada desde la dimensión histórica, y justificable per se). 
Se considera generalmente el desierto de Atacama como un extenso llano encerrado entre dos cordilleras: la de la costa i cordillera de los Andes. Esta idea está mui lejos de ser exacta. La parte interior del desierto no se compone únicamente de llanuras; contiene además numerosas serranías que se estienden de una cordillera a otra i la dividen en grandes hoyas hidrográficas limitadas por cadenas transversales, cuya dirección es aproximativamente la del noroeste al sureste. Entre los paralelos 23 y 27 existen cuatro de estas hoyas, en las cuales se ven todavía los cauces de los antiguos ríos que regaban estas extensas rejiones?

Las anotaciones sobre el litoral del desierto de Atacama de Vidal Gormaz no hicieron más que ratificar el cuadro conocido. Fueron estos los textos que utilizó el gobierno de Chile para desestimar otros esfuerzos científicos u exploratorios en la zona (González Leiva 2007). Nada valioso había hasta que en 1857 se tuvo la primera noticia del descubrimiento salitrero realizado por Domingo Latrille. En 1865 José Santos Ossa fijó la clave de las potencialidades de las entrañas del desierto. La ciencia determinaba de modo irrefutable que nada podía cambiar la noción del desierto de Atacama y esta fue una imagen arraigada en el inconsciente colectivo de los no-nortinos.

El primer poema relativo al desierto de Atacama tampoco contribuyó a enmendar la imagen establecida por la ciencia. Carlos Walter Martínez (Vicuña Mackenna 1978: 243-244) publicó en enero de 1867 sus versos que aluden a:

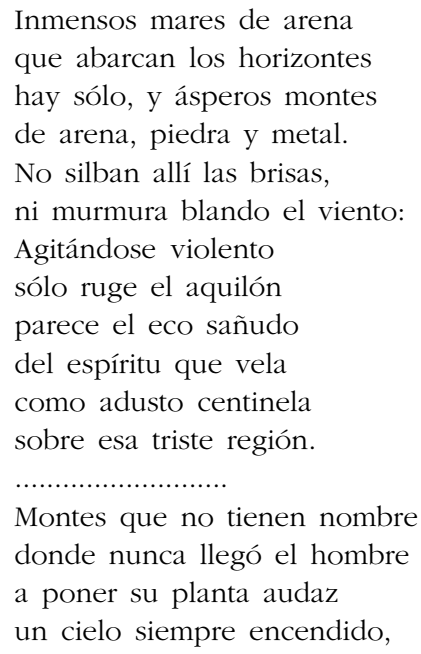

\footnotetext{
7 Es la versión castellana de Pedro J. A. Pissis, Salpetres et guanos du Desert d'Atacama: measures prises par le government chilien pour en faciliter l'exploitation, Imprimerie de Ch.Lambert, Saint Dennis, 1877. La obra le fue encomendada por el ministro del Interior, José Victorino Lastarria, que conoció la zona en esa década.
} 
siempre un sol resplandeciente que torna en piélago ardiente el anchuroso arenal.

Una vez incorporado el territorio a la soberanía chilena, como corolario de la guerra del Pacífico (1879-1884), y constatada la inmensa riqueza minera del páramo, las condiciones físicas del desierto prevalecieron con múltiples pormenores en dos autores relevantes para el conocimiento acabado del espacio nortino. Así, el ingeniero Alejandro Bertrand publica su Memoria sobre las cordilleras del Desierto de Atacama y regiones limitrofes en 1885 y otro colega suyo, Francisco J. San Román, su Desierto $i$ Cordilleras de Atacama, en 1896. Importa detenerse en esta última obra, pues San Román (1896: III-IV) acota una covarianza entre lo que se entiende por desierto con el conocimiento que permiten los pueblos e industrias asentados en dicho espacio. Escribe:

El largo trecho de territorio chileno que corre desde el agreste valle del Huayco hasta las pampas salitrosas por donde corre el río Loa, comprendiéndose entre ambos límites estremos todo lo ancho de Chile que se estiende desde las costas del Pacífico hasta la cresta de los Andes, constituye lo que propiamente se tomaba por Desierto de Atacama hasta principios del presente siglo.

Ha venido restringiéndose esta denominación mas i mas hacia el norte a medida que el progreso general i los descubrimientos mineros poblaban o hacian accesibles a la exploración aquellos territorios, fundándose pueblos i creándose industrias en ellos; mas, como mero título geográfico i sobre todo como significación de una zona de aridez i de producciones exclusivamente debidas al reino mineral, la tradición i la costumbres conservan aun aquella denominación para toda esa comarca que hoy abraza dos provincias chilenas, Atacama i Antofagasta.

Interesante es el tránsito paulatino desde la negatividad de la percepción del desierto — centrada exclusivamente en los factores climáticos- hacia la configuración de lo humano como significante del desierto a partir precisamente del descubrimiento y explotación del salitre. Un hiato en los tópicos descriptivos que en el texto de San Román presenta la disyuntiva del imaginario social nacional. Lo que la ciencia y los estudios establecen como demarcaciones del desierto y lo que la costumbre y la tradición han señalado como lo constitutivo en cuanto a superficie del desierto. Esto último conjuga los dos niveles. El racional, lo intencional de la acción estatal en cuanto a la discusión de los límites con Bolivia y que la Constitución de 1822 ya señalaba como frontera nacional hacia el norte, el despoblado de Atacama. Y lo percibido por los mineros de la provincia de Atacama y sus incursiones hacia el norte y la mutación del imaginario en conciencia del terruño entre los asentados en el despoblado. 
Pero no todo estaba resuelto sobre este imaginario. Cuando se debata en el Congreso Nacional a mediados de 1888 la creación de la provincia de Antofagasta, la oposición a ésta esgrimió la inviabilidad de incorporarla en la estructura político-administrativa del país en igualdad de condiciones a las restantes provincias, pues nada existía en el desierto. La civilización no había llegado y por ende perduraban las anotaciones tópicas de las condiciones del áspero y rudo territorio. La Comisión Consultiva del Norte (Salas Lavaqui 1904), en su informe relativo a la provincia de Antofagasta, reiteró el diagnóstico agudo de la inestabilidad de la cultura en el territorio:

El tránsito de la Comisión, por Antofagasta y por Taltal, en cuya pampa visitó las oficinas Chile y Ballena, si bien muy limitado en cada una de estas localidades, ha permitido verificar con respecto a ellas, los hechos principales que interesan a la Comisión [...] La naturaleza ofrece el tesoro del salitre al precio de un trabajo costoso y de sacrificios personales. En la Pampa según es sabido, no existen ciudades de importancia; los pueblos son escasos e insignificantes, y no parece posible que éstos se incrementen, ni menos aún que lleguen a convertirse en verdaderas ciudades [...] En la vida del desierto no se deja sentir con eficacia la intervención moderadora de los agentes naturales de toda cultura, a saber, la mujer, la familia, la propiedad distribuida entre muchos, la diversidad de las transacciones y de los negocios, y en suma, las satisfacciones de diverso orden que un nivel común de educación y moralidad trae consigo.

EL IMAGINARIO SOCIAL REGIONAL. LA SIGNIFICACIÓN Y LOS VALORES EN LA POSITIVIDAD DEL POBLAMIENTO DEL DESIERTO

¿Cómo fue posible que actores sociales distintos y la sociedad regional en su conjunto pudieran construir y concordar con las formas de una imagen distinta del desierto? Las respuestas son disímiles y encierran todas las posibilidades que brindaron el desierto y sus riquezas a los nuevos pobladores. Todos alcanzaron a vislumbrar el sentido de su estadía en el páramo. Para unos fue la eventualidad de un mundo nuevo, alejado de las injusticias de los campos chilenos. Otros repararon en la creación de una institucionalidad que apuntara no sólo a la protección sino a amalgamar la cohesión social ante el espacio. En fin, la posibilidad de mostrar todas las potencialidades del ingenio y trabajo del chileno al lado de los europeos. Dotar de sentido a las vidas era dar significación al espacio adonde se llegó. Si éste era inútil, entonces la existencia estaba perdida; si cabía alguna utilidad bien valió la pena escrutar sus superficies y grietas. La vida minera quedó sujeta al vaivén de los riesgos de la riqueza y sus fluctuaciones bursátiles. Quien sabía leer el desierto — en cuanto a su orientación- podía sobrevivir; quien no lo respetaba en su inmensidad y espejismos era un temerario sin rumbo. Fue la diferencia ontológica entre el baqueano y el intruso. 
Todos los habitantes de la costa y del hinterland de Antofagasta constituyeron una "tribu" en el sentido que le otorga Michel Maffesoli. Una concertación de sujetos que establecieron un vínculo a través de lo imaginario. De acuerdo con Maffesoli (2003: 152), "el vínculo se configura alrededor de imágenes que compartimos con los demás, puede tratarse de una imagen real o de una imagen inmaterial, o incluso de una idea con la que comulgamos, cualquiera que sea".

El desierto claudicó ante la embestida de ensoñación de los mineros. Fueron ellos los que otorgaron nuevo simbolismo al páramo. Sólo con esfuerzo imaginativo, actividad creadora, perseverancia laboral se logró mutar el significado rígido, lógico del yermo. Se trató de mostrar la inventiva de lo cultural en un espacio reticente a testimonios históricos; inventiva que somete a un cuestionamiento incisivo los valores arcaicos. Para habitar el desierto es preciso tener una postura distinta respecto a éste, comenzando con hacer trizas la imagen de negatividad y al mismo tiempo reinventar los conceptos éticos. Hablar de orden en el desierto no es suscribir el orden natural ni social aristotélico, sino al contrario el procedente del positivismo de Augusto Comte. Las potencialidades humanas irán de la mano con la técnica, la idea de progreso, de nueva institucionalización. En la prédica de José Victorino Lastarria (1871: 5-6), en sus memorables Cartas desde el mineral de Caracoles, fue donde cuajó la imagen de los chilenos en el desierto y Mejillones, como los nuevos yankees: "Que de día trabajan y de noche organizan sociedades de instrucción primaria, y discuten sobre todos los medios de hacer progresar la comunidad".

La transformación humana sólo se pudo lograr lejos de la hacienda, del inquilinaje, de la vida apacible santiaguina, de las costumbres coloniales. De ahí que la revalorización del desierto se contrapusiera al locus del campo del valle central chileno. Cuando la industria del salitre se arraigó en los arenales del páramo se consideró que la historia cambiaría la cronología de este paraje. Óscar Bermúdez (1963: 19), el historiador del salitre, un pampino agudo conocedor vivencial y documental de las oficinas salitreras, pudo anotar a principios de 1960:

El ambiente geográfico de esta región conformó primeramente las formas de vida de las primitivas culturas que allí fueron capaces de adaptarse e, incluso, de imponerse al medio. Allí los españoles pasaron siglos sobrellevando de mala gana su soledad y las dificultades impuestas por las grandes distancias. Más tarde se estableció una industria, la del nitrato de soda [...] Pero ni las poblaciones antiguas, ni la moderna industrialización salitrera y cuprífera, han modificado lo más mínimo el paisaje del desierto.

La articulación del imaginario social regional se logró con la conjunción de todos los habitantes del desierto. El Estado en cierta forma sintetizó la 
incomprensión nacional ante lo emprendido en el desierto. Fue desde el desierto de Atacama como surgió la idea de reivindicación del territorio para la soberanía chilena. Un concepto caro de los hombres que con sus capitales y mano de obra contribuyeron a la riqueza del país. Detrás de aquella noción se respiró ideológicamente su oposición tenaz a los gravámenes a sus industrias e incumplimientos de franquicias por parte del Estado. Todo ello hizo fluir las distintas percepciones comunitarias sobre la sociedad, el Estado, desde la situación concreta de mineros, comerciantes, habitantes del desierto de Atacama. Estos golpes, reacciones, claudicaciones, etc., entre la región y el Estado hicieron adquirir una común cenestesia (percepción correcta de su entorno y de sí mismo) (Cassian et.al. 2006) en los pobladores en lo que concierne a la región.

Un perspicaz político antofagastino, Belisario García (1921: 153) apuntó a esta asociación de tragedia, donde se mezclaba lo geográfico con las deplorables condiciones laborales de los obreros:

Los que estudian la pampa desde lejos se imaginan que existe realmente una Pampa Trágica [alude al título de la obra de Víctor Domingo Silva], cuyos dolores asumen las proporciones de un grito del Apocalipsis. Nada de eso es efectivo: los dolores de la Pampa son dolores que he visto en Santiago, en Valparaíso, en Talca [...] Son dolores que nacen de circunstancias que todos conocen, que todos palpan [...] La altura, el silencio, la latitud, la aridez no son fenómenos que crean el capitalista, ni la prensa salitrera. Son simples efectos de una situación de Geografía. La rudeza del trabajo, la vejez prematura, la neurastenia, tampoco son efectos de las exageraciones absorbentes del capitalista. La prostitución, el alcoholismo, la falta de escuelas, la inmoralidad social del ambiente, son un mero resultado de la inercia de los gobiernos, de la incapacidad de los partidos y de la cobarde complacencia de todo el mundo.

Esto se tradujo en distintos niveles. La defensa política de la región, la aspiración del territorio a ser provincia, la crítica al centralismo administrativo. Pero, también el contraste de lo construido en el desierto y lo habido en la nación. Fue Matías Rojas Delgado, el más connotado y tenaz defensor de lo regional, el que sostuvo la defensa del hombre del desierto. En su opinión, era imposible disociar la región minera de la proeza humana del desierto. Cada entidad realzaba la magnitud del enfrentamiento. En un manifiesto de 500 vecinos de Antofagasta, dirigido en 1876 al Congreso chileno a través de José Victorino Lastarria, afirmaban tajantemente:

El rudo obrero del desierto, el infatigable explorador, el abnegado minero, el ciudadano empobrecido i desterrado, no os piden por la voz autorizada del senador de Coquimbo un auxilio del tesoro para hacer alamedas, construir palacios o disiparlo en fiesta, ellos os piden para arrancar a la roca un poco de agua que apague su devoradora sed, ellos os lo piden para tener un albergue en sus horas 
de fatigas i de decepción, ellos os lo piden a fin de prolongar la fecundidad de su sudor hasta la hora del éxito que lo será ante todo para la patria ${ }^{8}$.

El desierto es fuerte. Puede derrumbar cualquiera incipiente vida cultural. La precariedad de los asentamientos es coherente con la vida nómada de los habitantes del desierto. Esta imagen todavía pervivía cuando la República está en vísperas de celebrar su primer centenario de vida. De ella se hizo eco Luis Silva Lezaeta, primer obispo de Antofagasta:

En este vasto y aridísimo desierto no hay una población arraigada: las familias son nómadas y nadie piensa en vivir por mucho tiempo en lugares donde no hay vegetación ni ninguno de los lugares de los atractivos que deciden a subsistir para siempre en estos inclementales lugares. Los chilenos y los europeos vienen atraídos por momentánea aspiración de mejoramiento de fortuna. Otros porque son aventureros que a causa de su mala conducta no pueden medrar en su propia patria. En general pueden estas poblaciones ser consideradas como grandes campamentos de obreros, la mayor parte solteros y sin familias [...] Las poblaciones de Tarapacá y Antofagasta están en idénticas condiciones físicas y morales: vida en el desierto, habitantes nómadas, agrupaciones de obreros sin familia, etc. Hoy se levanta aquí una ciudad y mañana, agotado el caliche o el mineral, hay que deshabitarla y vuelve allí el desierto con todos sus horrores?.

Esta defensa del territorio, aún en constante lucha por establecer una vida urbana que superara las condiciones de existencia de los campamentos mineros, se prolongó a lo largo de la primera mitad del siglo xx. El Comité Pro-Ferrocarril de Antofagasta a Salta (Gajardo 1924) hacía notar en la década de 1920, al Congreso Nacional, que el pueblo de Antofagasta:

No está dispuesto a que se le arrebate la oportunidad de crear su vida económica estable fomentando sus fuentes de riqueza y cumpliendo con los brillantes destinos que le señala su posición geográfica.

Esta última referencia surgía precisamente por el intento de interconectar el desierto con las regiones del noroeste argentino, una premonición de los actuales corredores bioceánicos hacia el interior del continente sudamericano para la salida de la producción hacia los mercados asiáticos. El paisaje y el hombre fueron defendidos en su conjunto por el Comité de Defensa

${ }^{8}$ Cf. El Caracolino, Antofagasta, 18 de septiembre de 1876. El poeta antofagastino Manuel Durán Díaz (1997: 50) asoció un rasgo climático con la acción del centralismo político, en su poema "Carta Norte (II)": "Por el cielo siguen y pasan las furgonetas de las nubes / con centralistas burócratas que dicen lo de siempre: 'Para esta zona no llega el presupuesto de las lluvias"'.

9 Oficio de Silva Lezaeta al representante de la Santa Sede en Santiago, Oficio n. $\stackrel{0}{86}$, Antofagasta, 19 de junio de 1908. Archivo del Arzobispado de Antofagasta, Libro IV Copiador de Oficios, años 1908-1912. 
de Antofagasta en la década de 1930. Para el Comité, más allá de la materialidad de las riquezas como sustento económico del poblamiento, existía otra razón para defender a la ciudad ante la adversidad de la depresión salitrera: toda ciudad constituye un conjunto de personas, cuyas emociones y sueños eran motivo para demandar la atención del Estado ante los ingentes esfuerzos pretéritos de la región hechos por el país.

LOS CONTRARIOS EN LA REFERENCIA DEL IMAGINARIO SOCIAL REGIONAL EN EL SIGLO XX

La humanización del páramo significó cambiar provisionalmente la fisonomía superficial de éste, dado que lo perenne y atemporal constituye lo sustantivo de esta geografía, el condicionante de larga duración en la percepción humana de las latitudes entre Calama y Antofagasta. Sin embargo, también se plantearon dualidades en el imaginario social regional en las primeras décadas del siglo xx. Se pudo verificar la contradicción entre los científicos europeos que miraron el desierto, precisamente en una zona que pasaba por ser la más "débil" en el poblamiento salitrero a principios del siglo $\mathrm{xx}$, y la afirmación de un grupo de habitantes de Antofagasta que defendía la unidad emotiva/perceptual respecto del desierto. Luis Darapsky (2003: 13), geólogo alemán, comparó lo que afirmara Tácito acerca de los germanos y su territorio con lo no-habido en el desierto como continuidad de un relato o narración que uniera en el tiempo a esta área. Afirmó rotundamente:

El primer aspecto del desierto es deprimente o impresionante. El desierto carece de historia. Ni siquiera posee tradiciones.

Esta anotación constituía el reverso del desafío que mostró Juan López - el primer habitante de Antofagasta en 1866 - cuando, en su celebérrimo Memorial de 20 de septiembre de 1872, hizo saber que, "al contemplar sus desiertos amenazadores, no se me ocultaron los obstáculos y dificultades con que tenía que luchar". En esta senda, los continuadores de López, el Comité de Defensa de Antofagasta (1936: 18), pudieron ratificar, a mediados de 1936, de qué manera el ingenio empresarial y el espíritu de los operarios, habían generado una historia en el desierto, poniendo todo en ella:

¡Los buenos tiempos de la antigua Compañía de Salitres, de grata memoria para todos los habitantes de este pueblo!

¡Los tiempos en que Jefes, obreros y empleados se encariñaban con la pampa como si hubiesen nacido en ella.

Pero la imagen revelaba una sintonía entre el tiempo identitario y el tiempo imaginario, donde se forjaría una comunidad en la pampa salitrera. Nostal- 
gia que se trastocará en "artificial" presente cuando, a mediados de 1950, la administración norteamericana de las oficinas salitreras Pedro de Valdivia y María Elena imponga la distinción entre los de "acá" y los de "allá", signando una fuerte carga de inclusión a los que laboraban en sus fábricas, "verdaderos pampinos", para contraponerlos a los foráneos, "no-apampados", que venían a alterar el orden establecido en el cantón del Toco (González Pizarro 2003). Sin embargo, el tránsito para llegar a la dicotomía descrita había sido mucho más áspero y largo.

Alrededor de 1906 comenzaron dos procesos desiguales en la pampa salitrera: uno tendente a la desnacionalización de la propiedad salitrera a favor de los capitales extranjeros, y otro a la recepción de un movimiento migratorio que conllevó paradójicamente al enganche de grandes contingentes humanos para las oficinas, mientras otros se debían alejar definitivamente de la pampa. Así, se empezó a notar un fuerte extrañamiento en el sentimiento de los pampinos: eran extranjeros en su propio suelo, no podían asumir como suyo nada, ni siquiera su trabajo y menos su vida.

Un empampado notable, Isaac Arce, el mejor conocedor de la pampa calichera antofagastina, que evaluó las estacas de la Compañía de Salitres entre 1904-1906, fue expulsado de ésta al ser enajenada y desaparecer la gran empresa chilena en Antofagasta. Era "el único que podía hacerle sombra por mis conocimientos de los trabajos y de la pampa en general", anotó amargamente (en González Pizarro 2004: XXV). Los trabajadores de la Mancomunal de Obreros, por medio de un volante propagandístico de 7 de octubre de 1904, definieron a la pampa antofagastina como su Port Arthur - en alusión al lugar estratégico que los japoneses arrancarían a los rusos en su guerra contemporánea- donde "sus soldados que se ven sepultados bajo la candente chusca del desierto [...] se ajita entre nosotros un solo sentimiento i cuyo [sic] es el ver el horizonte proletario cubierto por nuestras banderas". El panfleto lo guardó celosamente Arce. Su biografía quedaba entrampada, al igual que los mancomunalistas, en las arenas del desierto.

Esto demostraba la presencia hegemónica del capital extranjero y la ausencia patente de normas protectoras del trabajo: la pampa acogía y despedía a sus pobladores. Veía alzarse un día las vías férreas, chimeneas, asentamientos humanos —como por "encantamiento", describían sus testigos lo visto en 1906-1907- y, al siguiente, la desolación, la paralización de las actividades, el abandono de todo, incluidas las demarcaciones políticoadministrativas-religiosas ${ }^{10}$. La naturaleza controlaba como diosa Minerva los

10 Silva Lezaeta, otro empampado, registró en 1906: "El extraordinario desarrollo industrial que ha experimentado la provincia de Antofagasta en el último tiempo ha traído como consecuencia la formación de nuevos centros en lugares antes desiertos" (en González Pizarro 2005: 66). 
mínimos de existencia humana en su territorio y aguardaba el enfrentamiento con el último esfuerzo humano, la introducción de la novedosa tecnología para poder permanecer en el desierto. J. A. Peeples (1942: 2063), el ingeniero norteamericano a cargo de los nuevos procedimientos en las oficinas salitreras Pedro de Valdivia y María Elena, trazó las pérdidas y las eventuales victorias en tal lucha:

Era costumbre, al examinar terrenos para extracción a mano, hacer pequeños hoyos para muestrear [...] Se dejaba mucho margen al muestrero para ejercitar su juicio personal respecto a la cantidad y ley de caliche encontrado en cada hoyo. Los muestreros, en muchos casos, se hicieron bastantes expertos en juzgar las posibilidades de los terrenos examinados [...] Para una faena con palas mecánicas se necesitaban datos más precisos [...] el procedimiento de cubicación tuvo que ser cambiado.

El bullicio costero, característico de las localidades asentadas en el litoral, contuvo las imágenes de lo vertiginoso del tiempo, al ritmo de las operaciones comerciales y de la forma de vivir con los últimos ingenios de la vida moderna. Aquello fue constitutivo de un tiempo identitario, la amplia conexión entre el ciclo salitrero y la vitalidad urbana, de Antofagasta, Tocopilla y Taltal. Cuando se detuvo aquella marcha, el desierto clamó a través del terral ${ }^{11}$ acallando las esperanzas de los espejismos para los pobladores del litoral, sincronizando su tiempo con el cierre de las grandes chimeneas de las oficinas salitreras. Algunos se alejaron de la urbe que no los acogió, como diría el poeta (Rendic 1990: 53):

$$
\begin{aligned}
& \text { La ciudad me ahoga } \\
& \text { con su radio estrecho. } \\
& \text { Entre cuatro muros } \\
& \text { yo vivir no puedo. } \\
& \text { ¡A la Pampa, madre, } \\
& \text { A la Pampa vuelvo! } \\
& \text { Allí es otra el alma } \\
& \text { bajo el limpio cielo. }
\end{aligned}
$$

El silencio esparcido por la crisis terminal salitrera del ciclo Shanks que coincidió con la crisis mundial, 1929-1930, se asentó en la pampa y en las urbes. Todo se durmió en estas últimas: las energías, la imaginación, el ánimo. El poeta local, Carlos Marcoleta, en su extenso poema "Tres sonetos

${ }^{11}$ El terral es definido (Bahamonde 1978: 354) como "Viento del desierto que baja desde las cumbres cordilleranas y arremete contra el páramo hacia la costa. Su fuerza es capaz de arrastrar los terrales que encuentra al paso y enceguecer a los viajeros, además de pincharlos con las piedras". 
a Antofagasta" de 1934, exclamará: "Tu pampa, que orgullosa fuera un día/ se ha dormido en su gloria decadente". La locución "dormir" viene a reforzar semánticamente esta detención abrupta de los sueños surgidos de los músculos de los habitantes. En 1929 se canturreó en Antofagasta una canción emblemática — "Antofagasta dormida" - en la que unos versos aludían a "tus calles desiertas", trayendo al inconsciente colectivo el triunfo de la naturaleza sobre lo edificado durante décadas.

Hacia el interior de la entonces provincia, en un pueblo colonial llamado Toconao, ajeno a estos vaivenes bursátiles y a los quebrantos de la modernidad, podía percibirse todavía en 1936 la perduración del tiempo identitario. Un viajero eclesiástico (Cifuentes 1936: 16) narró la mutación entre lo avanzado por la industria en el desierto y lo exhibido al aproximarse al pueblo colonial:

Hemos llegado hasta allá por caminos solitarios; ni siquiera nos han acompañado las interminables hileras de postes que sostienen las líneas vibrantes, unión de vida a la distancia [...] Vida oculta en la quebrada. Allí hay sobre todo paz, mucha paz [...] Porque los habitantes de Toconao pasan sólo preocupados de sus huertos, que son su vida. Esos habitantes están identificados con sus árboles, de cada uno de los cuales conocen sus años y su historia.

El desierto fue carcomiendo al tipo humano que se atrevió a desafiar sus dominios y terminó comprendiendo el sentido de la naturaleza. Gustaba decir Salvador Reyes (1969: 291) que el hombre nortino era alegre y generoso, contradiciendo la aspereza del suelo nitroso, y al atardecer dejaba destilar su melancolía indefinida:

El hombre entra en sí mismo y se siente sólido, tranquilo y vasto porque su dimensión interior es la del mundo que lo rodea. Y de ahí viene su oscura melancolía, como un deseo de estar en otra parte, en otra sierra, en un puerto, en un oasis [...] Eso porque el nortino es el más andariego de los chilenos. Raro será el que no conozca la región palmo a palmo.

El dejarse deambular por los arenales en pos del anhelado trabajo en distintos cantones calicheros supuso que el pampino fuera caminante sólo cuando vio en la inmensidad de las soledades del desierto horizontes de fábricas salitreras todavía con sus calderas calientes. Fue el hombre rudo y robusto que el trabajo de los cachuchos y la barreta forjó en el norte salitrero. Era el tiempo imaginario de personajes anónimos que Sabella (1978: 114) rescatará con versos apasionados en su poema "Habla Abilio Rojas, antiguo pampino":

En esta pampa fatigué las manos,

me tutearon el combo y la barreta.

Era mía la boca de la grieta,

mío el viento de labios casi humanos. 
Este comenzó a desdibujarse cuando el tiempo identitario se resquebrajó por el marco histórico de la crisis general de la industria salitrera. Las paralizaciones de las oficinas conllevaron clausurar el tiempo histórico del ciclo clásico del nitrato. Ello supuso, además, provocar una sincronía en un proceso ascendente del tiempo diacrónico en el desierto. El corte fue fulminante. Concluía un tiempo identitario en la depresión intermedia de la provincia de Antofagasta. Aquello borró las señas de los hombres. Se terminaba la historia. El polvo volvió a enseñorearse sobre los muebles que administraron precariamente el tiempo en el espacio de siempre. Alberto Cabero (1948: 38-41), el abogado radical y ensayista radicado entonces en Antofagasta, en las notables conferencias que dictara hacia fines del decenio de 1920 en la "Extensión Cultural" de la capital regional, advirtió del fenómeno:

El hombre del Norte es un aventurero de tez bronceada por el viento y el sol, corazón temerario, siempre generoso, arrogante, intrépido [...] Sin embargo, este tipo robusto y viril va desapareciendo. Las frecuentes crisis salitreras han producido los paros forzados que, como una tormenta, esparcieron por el país el rebaño humano que la necesidad y la codicia agrupa.

El hombre se retiraba de Antofagasta, una ciudad situada, como expresaría el francés André Bresson (1997: 152) en 1886, entre dos desiertos: ¡las soledades oceánicas y las soledades terrestres!

El repliegue humano ante la naturaleza motivó al escritor Horacio Serrano Palma, en la década de 1950, a plantearse varias interrogantes sobre los nexos entre la naturaleza y el hombre chileno, para arribar finalmente a concluir que el país contaba con múltiples aspectos positivos que le daban un sitio destacado en el continente; empero, este pueblo "está siendo vencido por el propio medio natural que conquistó" (Serrano 1952:122).

HaCia la CONSTRUCCIÓN DE Un CRUCE DE imaginaRIOS. La REPRESENTACiÓN DE LOS POETAS

Fue Salvador Reyes quien sentenció que Antofagasta - y por extensión el desierto- era una tierra para vivir y morir. Carlos Pezoa Véliz expuso en 1905 que la desolación del desierto producía un contrapunto con la ciudad bulliciosa y, paradójicamente, la decisión no era escapar del páramo, sino volver a "la tranquila vida del desierto, tan desolada pero pura". Una tierra de tanto cromatismo y de engañosas apariencias provenientes del terral, la camanchaca o de los espejismos, no fue indiferente a la poesía mayor del país. Gabriela Mistral apostrofó en su "Breve descripción de Chile": 
El chileno, lo que él es, lo que puede sacar de sí, el chileno en volumen y en irradiación de energía, hay que conocerlo en la zona salitrera o en la región antártica de la Patagonia (Mistral 1957: 154).

Pablo Neruda vinculó el desierto en el canto XXII de su poema "Aún" (Neruda 1992: II: 1051-1052) con la nada y el silencio:
Alguna vez, cerca de Antofagasta, entre las malgastadas vidas del hombre y el círculo arenoso de la pampa, sin ver ni oír me detuve en la nada: El aire es vertical en el desierto.
Yo allí solo, buscando la razón de la tierra sin hombres y sin alas, poderosa, sola en su magnitud, como si hubiera destruido una por una las vidas para establecer su silencio.

Sabella (1986: 40-43) cantó a la "Pampa abierta [donde] no es posible que nada se esconda a los ojos de la muerte" pero fundamentalmente al hombre de aquel desierto:

La pampa labra un hombre de esfuerzos, recio y de musculatura superior, distinto del hombre del mar, del campo o la montaña, un tipo suculento de hombre en paridad de violencias con el páramo, donde sus carnes se tostaron al rojo de un sol de manicomio... La naturaleza bárbara talló el cuerpo del pampino. El maquinismo destrozó la actitud reverencial. La respiración del progreso henchió el pensamiento pampino; las máquinas aparejaron la protesta y el libro aleccionador [...] El pampino es el chileno sublimado en el vasto crisol del desierto: mezcla de Patria y de Mundo.

Un similar tono, pero orientado hacia la dimensión cósmica, inspiró a Miguel Squella (1980), quien en su poema "Desierto sin tiempo" estableció una imagen sintética:

\footnotetext{
Marco el paso del tiempo

con mi paso

en la extensión inmensa del desierto

que si yo no pasara

en el silencio

y en soledad del vasto yermo,

todo sería igual a los comienzos

que no tienen un fin como lo eterno

Pero el silencio inmenso del desierto guardará en su recuerdo,
} 
que con mi paso le marqué en un momento

que como tantos otros

con otros pasos marcaron

y los hicieron encontrarse con el tiempo.

La voz lírica ha constituido otra vertiente que ha tendido a representar al desierto y su hombre en el tiempo. Es otro magma de los imaginarios, donde los elementos característicos del páramo posibilitan su transmutación en el tiempo y, a la vez, la conciencia del desierto depende de la imagen forjada de éste por los hombres en el tiempo. Y la tensión dialéctica prosigue en otros ámbitos, pero manteniendo lo esencial del imaginario perenne: la habitabilidad de aquello que por definición es inhóspito.

\section{BIBLIOGRAFÍA CITADA}

Allendes, E. 1880. Un viaje en los vapores de la Mala del Pacífico. Y una mirada al Desierto de Atacama. Santiago de Chile: Nacional.

Anta Félez, J. L. 1998. Atacama fin de siglo. Tres historias de vida y una bibliografía. Jaén: Universidad de Jaén.

Archivo del Arzobispado de Antofagasta, Libro IV Copiador de Oficios, años 1908-1912.

Archivo del Museo Nacional de Ciencias (Madrid), Expediciones, Caja Grande N.o 3, carpeta 22, año 1800 .

Bahamonde, M. 1951. "Toda la pampa es un solo camino", en De cuán lejos viene el Tiempo: 7-34. Antofagasta: Grupo Letras.

Bahamonde, M. 1978. Diccionario de voces del norte de Chile. Santiago de Chile: Nascimento.

Benavides, A. 1971. Seis años de vacaciones. Recuerdos de la Guerra del Pacífico: Chile contra Perú y Bolivia. 1879-1884. Buenos Aires: Francisco de Aguirre.

Bermúdez, Ó. 1963. Historia del salitre, desde sus orígenes hasta la guerra del Pacífico. Santiago de Chile: Universidad de Chile.

Bibar, G. de. 1966. Crónica y relación copiosa y verdadera de los reinos de Chile, hecha por... Transcripción paleográfica de Irving Leonard. Introducción de Guillermo Feliú Cruz. Edición facsimilar. Santiago de Chile: Fondo Histórico y Bibliográfico José Toribio Medina.

Bresson, A. 1997. Una visión francesa del litoral boliviano (1886). La Paz: Stampa Gráfica.

Cabero, A. 1948. Chile y los chilenos. Santiago de Chile: Lyceum.

Cassian, N. et. al. 2006. "Imaginario Social: Una aproximación desde la obra de Michel Maffesoli". Athenea Digital 9: 1-26.

Castoriadis, C. 1983-1989. La institución imaginaria de la sociedad. Barcelona: Tusquets. 2 vols.

Cifuentes Gómez, A. 1936. "Más allá de la Pampa...Un pueblo levanta su templo". La Revista Católica 816: 241-243.

Comité de Defensa de Antofagasta. 1936. "Antofagasta y el problema salitrero". Boletín

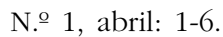


Darapsky, L. 2003. El departamento de Taltal. La morfología del terreno y su riqueza. Antofagasta: Consejo Nacional del Libro.

Dávila, A. et. al. 2004. "Bosque e imaginario social: aportaciones de/para su estudio en Euskadi y Aquitania", en VI Congreso Vasco de Sociología. Área de Trabajo 14. Sociología Rural y Sistema Agroalimentario. Bilbao.

Durán Díaz, M. 1997. 3 Dimensiones para mi tierra. Prólogo y selección de Sergio Gaytán. Antofagasta: Universidad Católica del Norte.

El Caracolino, periódico de Antofagasta, año 1876.

Frézier, A. 1902. Relación del viaje por el mar del sur a las costas de Chile i el Perú durante los años de 1712, 1713 i 1714 por M. Frézier. Traducido por Nicolás Peña. Santiago de Chile: Mejías.

Gajardo Cruzat, E. 1924. Album de Tarapacá y Antofagasta. Antofagasta: s.p.i

García, B. 1921. La verdad sobre los problemas económicos y sociales del Norte. Antofagasta: Skarnic.

González Leiva, J. I. 2007. "Primeros levantamientos cartográficos generales de Chile con base científica: los mapas de Claudio Gay y Amado Pissis". Revista de Geografía Norte Grande 38: 21-44.

González Pizarro, J. A. 1992. "Rafael Andreu y Guerrero", en Carlos Oviedo Cavada (dir.), Episcopologio Chileno 1561-1815: 299-326. Santiago de Chile: Universidad Católica de Chile. Tomo III.

González Pizarro, J. A. 2003. La pampa salitrera en Antofagasta. La vida cotidiana durante los ciclos Shanks y Guggenheim en el desierto de Atacama. Antofagasta: Corporación Pro Antofagasta.

González Pizarro, J. A. 2004. "Personalidad y obra de Isaac Arce Ramírez, historiador de Antofagasta", en Isaac Arce, Narraciones históricas de Antofagasta: I-LVII. Antofagasta: Corporación Pro Antofagasta.

González Pizarro, J. A. 2005. "Luis Silva Lezaeta y tres dimensiones de su pensamiento", en José A. González e Ignacio Sepúlveda (eds.), Luis Silva Lezaeta, el pastor del desierto: 43-78. Antofagasta: Universidad Católica del Norte.

Lastarria, J. V. 1871. Caracoles. Cartas descriptivas sobre este importante mineral dirigidas al Sr. Tomás Frías, Ministro de Hacienda de Bolivia. Valparaíso: de la Patria.

Maffesoli, M. 2003. "El imaginario social". Anthropos 198: 149-153.

Mariño de Lobera, P. 1960. "Crónica del Reino de Chile", en Crónicas del Reino de Chile: 227-563. Edición y estudio preliminar de Francisco Esteve Barba. Madrid: Biblioteca de Autores Españoles. Tomo 131.

Mistral, G. 1957. Recados contando a Chile. Obras Selectas. vol. IV. Santiago de Chile: Pacífico.

Neruda, P. 1994. Antología. Antología de Isidora Aguirre. Tomo II. São Paulo: Bibliográfica Internacional.

Peeples, J. A. 1942. "La extracción mecánica del caliche", en Anales del Primer Congreso Panamericano de Ingeniería de Minas y Geología: 2061-2072. Tomo V. Santiago de Chile: Universo,

Peña, A. 1952. "La pampa trágica". Mensaje I, 4: 572-574.

Philippi, R. A. 1860. Viage al desierto de Atacama hecho de orden del Gobierno de Chile en el verano de 1853-1854. Sajonia: Halle

Pissis, P. J. A. 1877. Salpetres et guanos du Desert d'Atacama: measures prises par le government chilien pour en faciliter l' exploitation. París: Ch. Lambert.

Rendic A. y S. Ivo. 1990. Obras Escogidas. Antofagasta: Universidad Católica del Norte. 
Reyes, S. 1969. Andanzas por el desierto de Atacama. Santiago de Chile: Zig-Zag.

Rojas, M. 1961. Obras Completas. Santiago de Chile: Zig-Zag.

Sabella, A. 1948. Centenario de J.K. Huysmans. Santiago de Chile: Universitaria.

Sabella, A. 1960. Clodomiro Castro, A las pampas salitreras. Antofagasta: HACIA.

Sabella, A. 1969. "Discurso inaugural del Seminario Internacional de Literatura Hispanoamericana", en La naturaleza y el Hombre en la Novela Hispanoamericana. Primer Seminario Internacional de Literatura Hispanoamericana: 11-26. Antofagasta: Universidad del Norte.

Sabella, A. 1978. Hombre de cuatro rumbos. Santiago de Chile: Nascimento.

Sabella, A. 1986. Semblanza del Norte Chileno. Santiago de Chile: Alfa.

Salas Lavaqui, M. 1904. Trabajos y antecedentes presentados al gobierno de Chile por la Comisión Consultiva del Norte. Santiago de Chile: Cervantes.

Saldivia Maldonado, Z. 2003. La visión de la naturaleza en tres científicos del siglo XIX en Chile: Gay, Domeyko y Philippi. Santiago de Chile: Universidad de Santiago de Chile.

San Román, F. J. 1896. Desierto i Cordilleras de Atacama. Tomo Primero Itinerario de las Exploraciones. Santiago de Chile.

Serrano Palma, H. 1952. Entre Mar y Cordillera. La lucha del chileno contra la naturale$z a$. Santiago de Chile: Marinetti.

Silva, V. D. 1938. La pampa trágica. Santiago: Zig-Zag.

Squella, M. 1980. Lugar de Sol, Arena y Sal. Antofagasta: Rimec.

Vicuña Mackenna, B. 1978. El Libro de la Plata. Buenos Aires: Francisco de Aguirre.

Vicuña Urrutia, M. 1995. La imagen del desierto de Atacama (XVI-XIX). Del espacio de la disuasión al territorio de los desafios. Santiago de Chile: Universidad de Santiago.

Fecha de recepción: 19 de agosto de 2008

Fecha de aceptación: 16 de junio de 2009 